fulvin. Concluding, there are several papers on the anti-tumour effects of some antibiotics together with some reports of clinical trials.

Unfortunately, there is no discussion, criticism or summarization of the tremendous amount of material presented. Hence, it is quite difficult to form an opinion of the latest ideas in antibiotic therapy. As partial recomponse, there is a very clearly set out table of contents which is probably of more value than the adequate index. I found the introductions too verbose and thought that the information contained in the 'panel discussions' should have been presented in a readable fashion. The book does give, however, an indication of the zest and enthusiasm that workers are putting into investigation of this field.

\section{TEACHING COMPREHENSIVE MEDICAL CARE}

By K. R. Hammond and F. Kern. Pp. xvii +642 . Commonwealth Fund: Harvard University Press. London: Oxford University Press. I960. 8os.

This publication from the University of Colorado Medical School will be welcomed as one of the first accounts ever given of a controlled trial in the field of medical education. The object was to discover whether participation in a family care clinic would help students to treat 'the patient rather than the disease.' The organization of the trial is described in considerable detail; then follows an account of the methods used by the Behaviour Research Laboratory in assessing the effects on the students' attitude and performance. There is inevitably some repetition, but extended summaries are provided which will increase the -value of the book to the specialist reader. It can be recommended to medical teachers as well as to sociologists and experimental psychologists.

\section{HARMFUL EFFECTS OF IONIZING RADIATIONS}

By Ethel Browning. Pp. vii + 1 58. Amsterdam: Elsevier Publishing Co. Distributed by D. Van Nostrand Co. Ltd. I960. I 5s.

In her preface Dr. Browning says her small book represents an endeavour to reduce the essential facts on ionizing radiations to reasonable proportions, and she has in fact succeeded in doing this.

The first two chapters describe the basic physics of radio-activity, the various units of radiation dosage and the maximum permissible dosage for external radiation and for radio-active materials deposited within the body. The problem of Strontium 90 fall-out is fully discussed.

The chapter on protective measures is interesting and informative, though perhaps the actual precautions to be taken by the workers should be more detailed, and further stress should be laid on the ' distance factor.'
One chapter is devoted to the various industrat applications of ionizing radiations.

The various biological hazards are fully discussed in the last four chapters, including the relationship of leukaemia to radiation and the dangers of genetic damage. Of particular inter $\overline{\text { बit }}$ is a full account, illustrated by several mic $\vec{\theta}-$ photographs, of the blood changes in those workif with luminizing agents.

The book is clearly printed on good paper, ead़ chapter has a full list of references and there is index. There are few factual errors. This boofk can be recommended to industrial medical officens and those concerned with the protection of workers in industry against ionizing radiations. It could also be read with advantage by senior medical awd postgraduate students as providing a concise stuर्षy on ionizing radiation and its dangers.

\section{PSYCHIATRY: DESCRIPTIVE AND DYNAMIC}

By J. A. SMith, M.D., F.A.C.P. Pp. 3402 . London: Baillière, Tindall \& Cox Ltd. Balgmore: The Williams and Wilkins Company. 1960. $56 \mathrm{~s}$.

The aim of this book is to describe the variows psychiatric syndromes and to make these both recognizable and understandable to students physicians. This naturally determines that a large part of the material is devoted to an expositionand explanation of the various schools of dynamoc psychopathology, and to illustrating the pathorgy at work in the various syndromes.

The first part of the book gives an admirabfy concise and readable account of the history of psychiatry which leads logically to a more detailed examination of the theories upon which psychological understanding and treatment of the patients are based.

The chapter headed psychodynamics is devoted to a detailed and accurate assessment of the theories of Freud together with definitions of the mental mechanisms involved which are exampless of lucidity.

The neuroses are then described, in a nowcontroversial style which greatly facilitates understanding and eliminates confusion-the only signipficant omission occurring in the chapter on hysteria in which the incapacitating condition of malignant hysteria, without loss of function, is not described.

The chapter on what are called psychophysige logical reactions is disappointing. These per. plexing conditions form a bridge between formad medicine and psychiatry and are of great interest to students and physicians. The new terminolo shows no advantage over psychosomatic, and phonetically less acceptable.

The value of devoting a chapter in such a book to psychotherapeutic techniques is doubtful, no student will attempt to practise without much fuller training and understanding of the techniques involved. It is surprising after reading 